\title{
Influence of resin curing cycle on the characterization of the tensile properties of flax fibers by impregnated fiber bundle test
}

\author{
Anurag Pisupati ${ }^{1,2}$, Abderrahmane Ayadi ${ }^{1,2}$, Mylène Deléglise-Lagardère ${ }^{1,2}$, Chung Hae Park ${ }^{1,2, *}$ \\ ${ }^{1}$ IMT Lille Douai, Institut Mines-Télécom, Polymers and Composites Technology \& Mechanical \\ Engineering Department, 941 Rue Charles Bourseul, 59508 Douai, France \\ ${ }^{2}$ Université de Lille, 59000 Lille, France
}

*Corresponding author's e-mail: chung-hae.park@imt-lille-douai.fr Telephone: +33 (0)32771 2187, Fax: +33 (0)327712981

\begin{abstract}
This study sheds light on the effect of resin cure cycle on the tensile properties of unidirectional flax fibers, which are assessed by the impregnated fiber bundle test (IFBT). The experimental protocol combines hand-layup and isothermal compression molding processes to fabricate unidirectional flax composites according to four different curing cycles. Isothermal and modulated DSC results indicate that the cross-linking reaction and glass transition temperature of the epoxy are affected by the resin curing cycle. SEM analyses before and after the tensile tests show that the improvement of the tensile properties of composites can be correlated to an increase of the fiber-matrix interfacial bonding. The results of the back-calculated tensile properties of flax fibers indicate that the application of the IFBT to untreated flax fibers depends on the mechanical interlocking between the matrix and the cell wall of the fibers.
\end{abstract}

Keywords: A. Biocomposites; B. Cure behavior; D. Mechanical testing; E. Compression molding 


\section{Introduction}

The ecologic concern and the demanding environmental standards have oriented the focus of research and development activities in the transport sectors towards biocomposites. In this context, flax fibers are more and more used to replace synthetic reinforcements such as glass fibers. Nevertheless, unlike synthetic fibers, the variability of intrinsic features of flax fibers requires extensive characterization and statistical analyses to assess their mechanical properties. Thus, there is still a need for reliable characterization methods before integrating them into structural applications [1-5].

Flax fibers are made of concentric layers of cell walls constituted of different biopolymers encapsulating an empty central channel known as the lumen. The main contributors to their mechanical properties are the cellulose microfibrils which are helicoidally embedded in a polysaccharide matrix [6-8]. Being extracted from plant stems, the development, maturity, and thus composition of this multi-wall structure depend on the climate condition and the cultivation season [9]. The extraction processes of fiber bundles from flax plants generally introduce the accumulation of micro-compressive defects such as kink bands (see white arrow in Figure 1) which increase the scatter of the mechanical properties [10-12]. The commercially available flax fibers predominantly correspond to an association of elementary fibers which form technical fibers with variable diameters and inevitably include the residues of cortical tissues [8]. In the literature, numerous studies have been conducted to characterize the tensile properties of flax fibers. The characterization methods can be classified into the tests performed on elementary fibers [12$15]$ and the tests performed on the bundles of technical fibers [16,17]. Elementary fiber tests require a high number of specimens and precaution during the isolation of each fiber [10,18]. Statistical laws representing the properties should also consider the geometrical irregularities and the density of kinkbands to guarantee a good agreement with the experimental data [12]. Fiber bundle tests are performed on multiple technical fibers affixed by pectin bonds. The tensile properties depend on the variation of the cross-sectional areas [19], and the tensile strengths are generally underestimated due to the slippage of elementary fibers along the loading axis [14].

To characterize the process-induced-properties of fibers and overcome the fibers slippage, impregnated fiber bundle test (IFBT) was recently reported to be a promising method applicable in the case of flax fibers $[18,20]$. According to this method, a priori assessment of the tensile properties of both UD composite and its matrix is required. The effective Young's modulus and tensile strength of the fibers are 
back-calculated using micromechanics models such as the rule of mixture. For this method, two conditions should be satisfied. From the mechanical point of view, the matrix should have a high ductility so that the failure strain of the matrix be higher than that of the fibers. From the processing point of view, a good impregnation quality with a negligible content of residual voids is required. In collaborative work among five laboratories, the back-calculated elastic moduli of flax fibers were compared and it has been shown that the IFBT method was more efficient than elementary fiber tests [18]. No apparent reason was found, however, to explain the scattering of the results for tensile strength [18].

In the literature, it has been found that the variability of the tensile strength of natural fiber composites can be related to different parameters which can be classified into three major categories [21]. The first category encloses the parameters affecting the intrinsic characteristics of flax fibers such as the change in cross-section due to swelling caused by resin absorption, moisture absorption or due to shrinkage caused by desorption. Elevated processing temperature (higher than $180^{\circ} \mathrm{C}$ ) can also cause a degradation of the mechanical properties of flax fibers [22-24] and a change in the helical angle of micro-fibril [25-27]. The second category is related to the parameters which can influence the mechanical properties of the matrix such as the curing condition in the case of thermoset matrix composites, by affecting the cure kinetics and the activation energy of the cross-linking reaction [28]. The third category is mostly related to the parameters affecting the interfacial bonding between the fibers and the matrix. In general, the interfacial bonding between natural fibers and epoxy can be explained by four principal mechanisms: molecular inter-diffusion, electrostatic adhesion, chemical bonding and mechanical interlocking [29,30]. The predominant bonding mechanism in the case of untreated flax fibers is the mechanical interlocking which is caused by mechanical anchoring of the matrix on the rough and non-uniform surface of the external cell wall of the flax fibers [26,31]. Also, surface fiber treatments such as alkali or silane treatments can help to produce free radicals on the fiber surface which can interact with matrix molecules by enhancing chemical and inter-diffusion bonding mechanisms [32,33]. According to Cadu et al. [34], the critical parameters affecting the mechanical properties of composites processed using the thermo-compression process are fiber conditioning, pressure level, cooling speed, mold exit temperature, and post-curing duration. To the best knowledge of the authors, the influences of some other parameters such as the curing temperature, heating speed and curing duration have not been investigated. 
The current study focuses on the influence of the cure temperature and duration on the back-calculated effective properties of an untreated flax tape according to the IFBT method. UD flax fiber composites were fabricated by hand-layup and isothermal compression molding according to four different curing cycles. Firstly, the impregnation quality was assessed to verify the validity of the two assumptions of the IFBT method. Secondly, mechanical tests were conducted on both the composite specimens and the neat matrix specimens to back-calculate the tensile properties of flax fibers. Finally, microstructure analyses were conducted to explain the causes of the scattered values of the tensile strength of flax fibers. Particular attention was paid to the fracture mechanisms and the interfacial quality to point out the modification of the interfacial bonding.

\section{Materials and methods}

\subsection{Materials}

Unidirectional flax-fiber tape (Flaxtape ${ }^{\mathrm{TM}} 110$, Lineo, Belgium) with an areal weight of $110 \mathrm{~g} / \mathrm{m}^{2}$ was used as the reinforcement. The UD flax fibers within the tape were maintained to be aligned by the reactivation of their natural pectin cement without application of any additional surface treatment. An epoxy resin (Prime-27, Gurit ${ }^{\circledR}$, Switzerland) was used to impregnate the fiber reinforcement. As recommended by the supplier, the resin was mixed with a hardener (Prime-20, Gurit ${ }^{\circledR}$, Switzerland) with a stoichiometric ratio of 100:28. This resin has a relatively low viscosity $\left(265-285 \mathrm{mPa} \cdot \mathrm{s}\right.$ at $\left.25^{\circ} \mathrm{C}\right)$, low exothermic reaction during the cross-linking reaction and limited shrinkage [35].

\subsection{Composites fabrication}

UD composite plates were manufactured using hand-layup process followed by isothermal compression molding using a hot press (Pinette, P.E.I., France). Neat epoxy plates and unidirectional composite laminates with 13 plies $\left([0]_{13}\right)$ were prepared according to four different manufacturing cycles. Each cycle comprised five consecutive steps (see Figure 2): cutting (1), drying (2), hand-layup (3), isothermal compression (4) and post-curing (5).

In the hand-layup process, dry UD flax tapes which had been dried at $60{ }^{\circ} \mathrm{C}$ for 14 hours, were placed in a rectangular aluminum mold with dimensions of $270 \times 40 \mathrm{~mm}^{2}$. In order to avoid the increase of the resin viscosity during the impregnation process, the mold was preheated to the same temperature as the curing 
temperature. Then, the resin mixture was gently applied by a roller on a dry fiber ply, and another dry fiber tape ply was placed on this resin layer in the mold. This procedure was repeated until the total number of plies was reached. Subsequently, the impregnation of fibers by the resin was driven by applying a constant pressure of six bars induced by the upper mold closing. In this study, the only differences among these cycles were the duration and the temperature of the isothermal compression step, which should be optimized to improve the impregnation quality by decreasing the viscosity and also to reduce the curing time of the matrix. The duration of the isothermal compression step was selected by trial-error tests to measure the gel time of the used epoxy during isothermal curing performed at different temperatures, viz. 25,60 and $80^{\circ} \mathrm{C}$ referred to as the "RT", "60" and " 80 " cycles, respectively. The corresponding durations were 1020, 80 and 40 minutes for "RT", " 60 " and " 80 " cycles, respectively. A second cycle at $80^{\circ} \mathrm{C}$ (" 80 s" cycle) was implemented with a reduced consolidation duration of 20 minutes. Post curing of the neat resin and composite specimens was conducted in a temperature-regulated oven to ensure the complete cure.

\subsection{Differential scanning calorimetry (DSC) measurements}

Isothermal DSC measurements were conducted at 60,70 , and $80^{\circ} \mathrm{C}$, to understand the cure kinetics of the epoxy during isothermal compression step and post-curing. Measurements at $25{ }^{\circ} \mathrm{C}$ were not considered because their corresponding isothermal compression duration was too long, viz. 17 hours. Two samples of 5 to $10 \mathrm{mg}$ of resin/hardener mixture were encapsulated in aluminum pans at $25^{\circ} \mathrm{C}$. The average duration from the start of the resin/hardener mixing to the start of each isothermal DSC measurement was fixed to 15 minutes. Each measurement sequence comprised a temperature ramp of $100{ }^{\circ} \mathrm{C} / \mathrm{min}$ from $25{ }^{\circ} \mathrm{C}$ to the target temperature which was then maintained for 90 minutes. This temperature ramp helped to achieve the target temperature faster by preventing the reaction of epoxy during heating. Dynamic DSC measurements were conducted to measure the glass transition temperature $\left(T_{g}\right)$ of the post-cured epoxy in the cured neat matrix and composite plates. Two samples of 10 to $12 \mathrm{mg}$ were submitted to two successive temperature sweeps between $25^{\circ} \mathrm{C}$ and $140{ }^{\circ} \mathrm{C}$ at $10{ }^{\circ} \mathrm{C} / \mathrm{min}$. All isothermal and dynamic DSC measurements were conducted on the same differential scanning calorimeter (DSC1, Mettler Toledo, USA) and under a nitrogen atmosphere. 


\subsection{Laminate quality assessment}

Out-of-autoclave manufacturing of laminate composites is known to induce residual void contents higher than $2 \%$. Thus, to evaluate the impregnation quality of the manufactured composite plates, density measurements and SEM analyses were considered.

Two samples of rectangular geometry $20 \times 40 \mathrm{~mm}^{2}$ were cut from each composite plate to measure the density of composites. The thickness of the samples was measured at each test. Dry mass $\left(M_{\text {air }}\right)$ and immersed mass ( $\left.M_{\text {ethanol }}\right)$ were measured using a microbalance (Mettler AE160, USA) with an accuracy of $10^{-4} \mathrm{~g}$. Ethanol with a density of $0.789 \mathrm{~g} / \mathrm{cm}^{3}\left(\rho_{\text {ethanol }}\right)$ was used as an immersion liquid. The density and void content $\left(V_{\phi}\right)$ of the composite specimens were calculated by Equations 1 and 2, respectively.

$$
\begin{gathered}
\rho_{c}=\frac{M_{\text {air }} \rho_{\text {ethanol }}}{M_{\text {air }}-M_{\text {ethanol }}} \\
V_{\phi}=1-\rho_{c}\left(\frac{w_{f}}{\rho_{f}}+\frac{w_{m}}{\rho_{m}}\right)
\end{gathered}
$$

where, $\rho_{c}, \rho_{m}$, and $\rho_{f}$ are the densities of the composite, of the matrix $\left(1.09 \mathrm{~g} / \mathrm{cm}^{3}\right)$ and of the fibers $(1.50$ $\mathrm{g} / \mathrm{cm}^{3}$ ) respectively. $w_{m}$ and $w_{f}$ are the weight fractions of the matrix and of the fibers, respectively. The fiber volume fraction $\left(V_{f}\right)$ of each composite was estimated using Equation 3.

$$
V_{f}=\frac{m_{f}}{\rho_{f} v_{c}}
$$

where $m_{f}$ is the total mass of fibers and $v_{c}$ is the total volume of the composite plate.

SEM micrographs based on secondary electrons were acquired using electron microscope (Jeol Neoscope 6000, Japan). Microstructure arrangement along the thickness of the composite plates was observed not only at a macro-scale (i.e. the length-scale of the plate's thickness) to detect residual voids but also at a meso-scale (i.e. length-scale of the technical fiber's diameter) to examine the fiber/matrix interface. The corresponding samples were cut using a band saw then gradually polished using a series of sandpapers (320/500/1200/4000 grit) and an alcohol-based lubricant (DP-Lubricant Blue, Struers Aps, Denmark). Finally, a thin layer of gold was sputtered. Complementary SEM analyses were also conducted after the tensile tests to examine fractured surfaces.

\subsection{Tensile tests}


All tensile tests were conducted at a uniform crosshead speed of $2 \mathrm{~mm} / \mathrm{min}$ on a universal test machine (Instron 1185 machine, USA) which was equipped with a $10 \mathrm{kN}$ load-cell and an extensometer with a gauge length of $50 \mathrm{~mm}$. At least five composite and five neat resin samples were tested for each manufacturing cycle. The composite samples had a rectangular geometry of $250 \times 10 \mathrm{~mm}^{2}$, whereas the neat resin samples were dog-bone-shaped as defined by the standard ISO 527-2. All the samples were conditioned at $23{ }^{\circ} \mathrm{C}$ for 24 hours at a relative humidity of $50 \%$. The rule of mixture, as described in Equations 4 and 5, was used to back-calculate the tensile properties of UD flax tape.

$$
\begin{gathered}
E_{f}=\frac{E_{c}-E_{m}\left(1-V_{f}\right)}{V_{f}} \\
\sigma_{f}=\frac{\sigma_{c}-\sigma_{m}^{*}\left(1-V_{f}\right)}{V_{f}}
\end{gathered}
$$

where the subscripts $f, m$, and $c$ represent the fiber, the matrix, and the composite, respectively. Becasue the epoxy used in this work is more ductile than the fibers, we can assume that the failure mechanism of the composite specimen is dominated by fiber breakage. Hence, it is necessary to calculate the stress in the matrix at failure $\left(\sigma_{m} *\right)$ as the product $E_{m} \times \varepsilon_{c}$. The application of such a procedure relies on the assumption of perfect interfacial bonding between the fibers and the matrix, while the residual void content is sufficiently low.

\section{Results and discussion}

\subsection{Physicochemical behavior of the matrix}

The cross-linking reaction of the epoxy exhibits two different thermal regimes (see Figure 3a). The first regime takes place for the first 60 seconds and marks the initiation of the cross-linking reaction. By increasing the temperature of the isothermal plateau from $60{ }^{\circ} \mathrm{C}$ to $80^{\circ} \mathrm{C}$, the reticulation reaction is accelerated as indicated by the increase of the corresponding areas of the exothermic peak, which are $13.4,17.4$ and $22.7 \%$ for 60,70 and $80{ }^{\circ} \mathrm{C}$, respectively. The second regime is marked by a drop of the heat flow and a slower advance of the cross-linking reaction as the heat flow tends towards an asymptotic level. To gain more insight in the curing kinetics of the epoxy during the steps four and five of the manufacturing cycle (see Figure 2), the degree of cure $\alpha(t)$ was calculated by Equation 6.

$$
\alpha(t)=\frac{\Delta H(t)}{\Delta H_{T}}
$$


where $\Delta H(t)$ is the heat of reaction at the time $t$ and $\Delta H_{T}$ is the total heat of the reaction of the epoxy mixture. In order to illustrate the change of cure kinetics during the isothermal compression, the value of $\Delta H_{T}(1159.8 \mathrm{~W} / \mathrm{g})$ was obtained by integrating the heat flow measured over time during the isothermal DSC test conducted at $80{ }^{\circ} \mathrm{C}$.

As illustrated in Figure $3 \mathrm{~b}$ which shows the time evolution profiles of the cross-linking reaction, the epoxy cure cycles exhibit two-step paths of different kinetics. Considering the manufacturing cycle " 80 s" as an illustrative example, the cross-linking reaction advances during the first step following the same profile of the cycle " 80 " (see Figure $3 b$ ) until it reaches the degree of cure of 0.58 at the end of the isothermal compression step (i.e., 1200 s). During the second step, viz. the post-curing operation, the advance of the cross-linking reaction follows the same curing rate as the cycle "70" (i.e. the same slope in Figure $3 b$ ) until it reaches the total cure of the matrix (i.e. $\alpha \approx 1$ ). The relative degrees of cure at the end of the isothermal compression step for the cycles " 60 " and " 80 " are 0.58 and 0.72 , respectively. The glass transition temperature $\left(T_{g}\right)$ values obtained from the dynamic DSC measurements also showed a high cross-linking level following the two-step curing cycle as mentioned earlier (see Table 1). All the glass transition temperatures of the neat matrix range between 71.5 and $78.2{ }^{\circ} \mathrm{C}$ (determined using tangent method) which is higher than the reference $T_{g}$ of $69.4{ }^{\circ} \mathrm{C}$ indicated by the epoxy supplier (see Table 1). Moreover, the cycle " 80 " seems to be as efficient as the cycle " 60 " concerning the cure kinetics despite its shorter curing duration. The increase in $T_{g}$ values could be due to the decrease in the activation energy of the system, thereby allowing higher cross-link density [28]. Similar results of the $T_{g}$ values which ranged between 75.2 and $82.5^{\circ} \mathrm{C}$, can also be verified from the composite samples. $T_{g}$ levels of the composite samples were higher than those of the neat resin samples (see Table 1). The corresponding increases of $T_{g}$ from composite samples to neat resin samples were 5.2, 2.2 and $6.3 \%$ for the cycles "RT" "60" and " 80 " respectively. In the literature, a few studies have indicated such an increase of $T_{g}$ values between 10 and $27 \%$ after the addition of natural fibers [36-38]. To the best knowledge of the authors, the reason for $T_{g}$ change has not clearly been explained in the literature, and more investigations are still required to verify some of the following assumptions. The increase of $T_{g}$ can be hypothetically attributed either to the reduction of the activation energy of the cross-linking reactions or to the enhancement of the thermal conductivity between the tooling and the core of the matrix due to the presence of reinforcements, which is usually in the case of synthetic fibers $[28,39,40]$. It could also be induced by an increase of the 
ratio of some functional groups at the surface of the natural fibers which may enhance the chemical bonding between the fibers and the resin molecules, therefore, restricting the movement of polymer chains. The latter cause seems to be more probable as the natural fibers have low thermal conductivity. Nevertheless, the same $T_{g}$ value for the resin and the composites processed by the cycle " 80 s" implies that more investigations are required to verify that assumption.

\subsection{Assessment of residual void content}

The results of void content measurement presented in Table 2 indicate that the adopted manufacturing cycle guarantees a good control over the fiber volume fraction (around $51 \pm 2 \%$ ) and the fiber distribution without resin-rich zone as shown by the SEM micrographs in Figure 5. Moreover, the increase of the curing temperature decreased the average void contents which were $1.9,1.7$ and $1.6 \%$ for the cycles "RT", "60" and " 80 ", respectively. At the same curing temperature, i.e., $80{ }^{\circ} \mathrm{C}$ in this case, the increase of the curing duration decreased the average void content (cf. the cycles " 80 " and "80s"). Nevertheless, the scattering of void contents highlights that the reproducibility of high-quality impregnation (i.e., void content $<2 \%$ ) is limited. Because the fiber drying and resin degassing were performed before compression molding process, this limitation seems to be related to the intrinsic structure of the flax fiber reinforcement, such as distorted or fractured technical fibers, which might potentially trap air pockets during hand-layup and the isothermal compression steps [41], as shown in SEM images (see Figure 4).

\subsection{Qualitative assessment of fiber-matrix interface}

Figure 5a shows the presence of a significant amount of macro-scale cracks despite the precautions made during the polishing (see Section 2.4). A basic image thresholding operation relying on the distribution histogram of gray levels of the SEM micrographs was applied via the open-source software ImageJ (NIH, USA) to highlight the network of cracks. Filtered images show that the large cracks are located at the interface between the matrix and the technical fibers. As described previously, the interfacial bonding between natural fibers and epoxy is in general explained by four principal mechanisms: molecular interdiffusion, electrostatic adhesion, chemical bonding and mechanical interlocking [29,30]. Because the fibers of flax tape used in this work were not submitted to any surface treatments, the mechanical 
interlocking, viz. a mechanical anchoring of the matrix on the outer surface of the flax fibers, is assumed to be predominant compared with the other interfacial bonding mechanisms.

Localized SEM micrographs near technical fiber cell walls (see Figure 5b) were used to inspect the structural arrangement of the outer cell walls of technical flax fibers near large cracks. The mode of the interfacial debonding between the technical fibers and the matrix is dependent on the curing temperature. In fact, in the case of the sample prepared by the "RT" cycle, macro-scale interfacial debonding between the matrix and the technical flax fibers exhibits a total separation between the matrix and the fibers without altering the external cell wall of the technical fibers. At higher temperatures $\left(60{ }^{\circ} \mathrm{C}\right.$ and $\left.80{ }^{\circ} \mathrm{C}\right)$, however, similar meso-scale debonding cracks seem to be associated with the partial separation of the outer layers of technical fibers from the matrix because the cell walls are partially torn off from the technical fibers. First, the variations of partially torn off cell walls between considered cycles agree with the results in Le Duigou et al. [42] where the authors indicated that epoxy resin penetration in the cell walls of Hermes and Electra flax fibers could reach up to $1.7 \mu \mathrm{m}$ and $2.2 \mu \mathrm{m}$, respectively, when polymerized at $65{ }^{\circ} \mathrm{C}$ during 14 hours. Second, the meso-scale SEM observations indicate the enhancement of the interfacial bonding between the matrix and the outer cell walls of some technical flax fibers as the curing temperature is increased. This interpretation concurs with the results of Li et al. [43] and Liotier et al. [44] where it has been concluded that better mechanical interlocking could be achieved by increasing the impregnation temperature which decreased the viscosity and the contact angle of the epoxy resin and subsequently increased the wettability of the flax fibers.

\subsection{Tensile properties of composites}

Figure 6 shows the typical two-slope stress-strain curves of the flax-epoxy composite samples. While the first slope is characteristic of the linear-elastic domain ranging between $0 \%$ and $0.1 \%$ of strain, the second slope is following the strain-softening domain between $0.2 \%$ and $0.3 \%$. According to the literature, this transition point in the slope of the tensile curve is referred to as the knee-point [45-47]. As suggested by Bensadoun et al. [18], two elastic moduli (referred to as $E_{1}$ and $E_{2}$ ) were calculated within the strain ranges of $0-0.1 \%$ and of $0.3-0.5 \%$, respectively. Theoretically, $E_{l}$ corresponds to Young's modulus, and $E_{2}$ corresponds to the stabilized elastic modulus following the stabilization of the intrinsic non-linear behavior of flax fibers [45]. Because the difference in fiber volume fraction among the 
composite samples obtained by the same manufacturing cycle was smaller than $3 \%$ which was statistically insignificant (see Table 2), the normalization of tensile test results based on the fiber volume fraction was not considered. The average values of $E_{1}, E_{2}$ and the tensile strength of the composite as well as of the neat matrix samples, are presented in Figure 7. The corresponding standard deviations represented by error bars are added to the same chart. The statistical significance of obtained data is verified based on the one-way analysis of variance (ANOVA) at 95\% confidence interval where (p-values are provided in Table S1 in supplementary data) because of the small number of tensile samples. The computed "p-values" which were lower than 0.05 confirmed that the change of manufacturing cycle affected the tensile strength and the elastic moduli of the composite samples.

Figure 7 indicates that the tensile properties were higher in the case of specimens obtained by the cycles "60" and "80" than by the cycles "RT" and "80s". From the cycle "80" to "80s", the tensile strength and the moduli $E_{1}$ and $E_{2}$ of composite have decreased by 23.6, 20.2 and $19.7 \%$, respectively. The origin of such decreases in the tensile properties is directly linked to the imposed dwell time under the pressure as the other process parameters were maintained constant. The decrease in the dwell time of the isothermal compression from 40 to 20 minutes may affect some mechanisms which can alter the interfacial bonding, such as the advancement of the resin curing and the penetration of the matrix into the cell walls of flax fibers.

The effect of the resin curing on the interfacial bonding can be excluded from the tensile test results of the matrix and of the composite samples manufactured by the " 60 " and " 80 s" cycles. Indeed, the similarity of the degree of cure (i.e. 0.58; see Section 3.1 and Figure $3 b$ ) at the end of step 4 for both manufacturing cycles, has resulted in a very small difference in the tensile properties of the neat matrix samples obtained by the " $60 "$ and " 80 s" cycles (see Figure 7). Given that the average moduli $E_{l}$ and $E_{2}$ are almost the same for the " 60 " and " 80 " cycles, the hypothesis of the matrix penetration into the cell wall of flax fibers is more convincing. Nevertheless, the similar values of $E_{l}$ and $E_{2}$ for the " 60 " and " 80 " cycles indicate that the resin penetration did not affect the stress softening region of the tensile behavior of the composite samples. Thus, resin penetration did not affect the stiffness of the elementary fibers, which is governed by hardening of pectin, gradual crystallization of cellulose present in fibers, etc. [45] The increase of the tensile strength of composite by $7.4 \%$ in the case of " 80 " cycle compared to the " 60 " cycle also implies that the depth of resin penetration has been increased by lowering the resin viscosity at the higher 
temperature. As a result, this has strengthened the mechanical interlocking between the interface between the external cell wall of technical fibers and the matrix as stated previously in Section 3.3. The same principle can apply to explain the difference between the " 80 " and " 80 s" cycles. Even at the same temperature, viz. $80{ }^{\circ} \mathrm{C}$, the time for resin penetration at the " 80 s" cycle was not sufficiently long and the mechanical interlocking effect was smaller than that in "80" cycle. For the "RT" cycle, the small tensile moduli are correlated with the weak mechanical interlocking as described in Section 3.3.

It has been widely known that elementary plant fibers have porous structures and absorb certain liquid through the fiber cell walls. As the liquid is absorbed into plant fibers, the fibers swell. Nevertheless, it is still difficult to directly observe the resin penetration into the fiber cell walls. Given the small thickness of cell walls and tiny pores on the surface of flax fibers ranging between 16 to 38 angstroms, extensive characterization studies are required for a comprehensive analysis [42,48].

\subsection{Qualitative analysis of fractured surfaces}

Figure 8 shows the fractographs of transverse fracture surfaces where the predominant failure mechanisms are supposed to be dependent on the manufacturing cycle. In fact, for the sample of the "RT" cycle (see Figure 8a), matrix cracks between technical fibers can be observed along with the presence of fractured fiber bundles and the neat surface of single fibers which were pulled out. This observation indicates a relatively weak interfacial cohesion between the matrix and the fibers. In the case of the samples prepared by the "60" cycle (see Figure $8 \mathrm{~b}$ ), we can observe elementary fibers decohesion and significant longitudinal breakage of technical fibers. It is clear that even when the fibers decohesion takes place, there is a significant amount of matrix surrounding the fibers. Also, the fractured surface of " 60 " samples show small fiber-like structures around the failed fiber regions. These thin structures are the outer cell-walls the fibers which were peeled off during the failure of the composites (see Figure 8b). In the case of " 80 " cycle, the presence of residual voids can be observed and the fracture surface shows a significant amount of peeled fiber cell walls (see Figure 8c), which implies a strong mechanical interlocking between the fibers and the matrix. This is also coherent with the observations made by Le Duigou et al. [42]. As mentioned in section 3.4, this proves the assumption of the improved mechanical interlocking. In Figure 8d, the decohesion between the matrix and flax fibers exhibits less peeling of cell walls than that of " 80 " cycle due to the high void content which was the precursor of composite failure. 


\subsection{Back-calculated flax fiber properties}

The IFBT method was adopted to investigate the influence of resin curing cycle on the tensile properties of flax fibers. In Figure 7, it can be noticed that the properties of composites exhibit significant changes according to the cure cycle, whereas the matrix properties remain constant. This implies that there is a change either in the properties of fibers or in the stress transfer between fibers and matrix. To understand these changes caused by the cure cycle, the back-calculation of tensile properties of fibers was performed. Conceding the assumptions of the rule of mixture such as the perfect interfacial bonding between the fibers and the matrix and the small residual void content, a threshold of $2 \%$ of void content was considered. Thus, back-calculated tensile properties of the flax fibers were computed only for the samples obtained from the cycles "RT", "60" and "80" which resulted in small void contents (see Table 2). Based on the results of the corresponding ANOVA test (see Table S1 supplementary data), significant differences at $95 \%$ level of confidence were only obtained in the cases of the tensile strength and of $E_{l}$ whereas the variance for $E_{2}$ was negligible (p-value of $E_{2}=0.41>0.05$ ). Figure 7 shows that the backcalculated flax fiber properties by the IFBT method of the " 60 " and " 80 " cycles had maximum relative variations of $10.5 \%$ for $E_{l}$ and of $7 \%$ for strength values, respectively. The fiber strength, in particular, was the highest in the case of cycle "80" (see Figure 7b). This difference of back-calculated strengths of fibers between the cycles " 60 " and " 80 " can be attributed to the change of interfacial bonding, as explained in sections 3.3 and 3.5. This result suggests that the reliability of back-calculated tensile strength of flax fibers is dependent on the mechanical interlocking between the matrix and flax fibers. To generalize this explanation to the scattering in the tensile strength results presented by Bensadoun et al. in [18], the computed values in this study were compared with those from literature (see Figure 9)

$[22,34,39,49-53]$. It can be verified that the highest strength of the impregnated fibers is obtained by cycle " 80 " adopted in this work. This result implies that $80{ }^{\circ} \mathrm{C}$ is a better curing temperature for the used resin system to improve the resin penetration into the fiber cell walls. Therefore, a better understanding of the resin penetration mechanisms is required before characterizing flax fiber properties, in particularly tensile strength.

\section{Conclusion}


The influence of the manufacturing cycle on the mechanical properties of flax-epoxy composites was investigated. The quality assessment of composites was carried out by measuring the void content of the laminates. The void content was found to decrease with increase in curing temperature. It was reported that the void contents in all the cases except for the cycle " 80 s" were smaller than two percent, which might not significantly degenerate the mechanical properties. This satisfies the first requirement to use IFBT. The second hypothesis of the good interface was examined by SEM observations. The fractographs supported the hypothesis of resin penetration into fiber walls because more cell walls were peeled off for the sample of the cycle " 80 " indicating an excellent fiber-matrix interfacial adhesion. The curing duration under pressure also played an important role to determine the quality of composites even at the same curing temperature, e.g., $80{ }^{\circ} \mathrm{C}$ in this work. The influence of temperature on the physicochemical behaviors of both neat epoxy and composites was also examined by the measurement of glass transition temperature whose value was higher for higher temperature cycle in both the cases of neat epoxy and of composite. It should also be noted that the composite specimens exhibited a higher glass transition temperature than the neat epoxy. It was observed that the processing temperature had a substantial influence on the tensile behavior of the composites. A linear trend was noticed between the processing temperature and the tensile strength of the composite. This increase in the tensile strength of fibers was attributed to the enhanced resin impregnation into the fiber cell walls at higher processing temperatures, which was verified by microscopy observations. The decrease in the tensile properties was related to the improper curing and increased void content of composites. The results of back-calculated properties clearly showed the dependence on the cure cycle. It was shown that if IFBT is adopted to characterize fiber properties, special care should be taken in the selection of cure cycle. Otherwise, the properties of flax fibers can be underestimated, which was the plausible issue in the literature. For future study, it would be interesting to investigate the depth of resin impregnation depending on the temperature and viscosity of the matrix as well as the fiber treatment and its effect on the estimation of fiber properties.

\section{Acknowledgments}

The first and fourth authors would like to thank the European Union (European Regional Development Fund FEDER) for the financial support to the BIOCOMPAL project within the framework of the INTERREG/FWVL program. The second, third and fourth authors would like to acknowledge the 
European Union (European Regional Development Fund FEDER), the French state and the Hauts-de-

France Region Council for co-funding the ELSAT2020 by CISIT project (POPCOM action).

\section{Conflict of interest}

The authors declare no conflict of interest.

\section{References}

[1] Charlet K, Baley C, Morvan C, Jernot JP, Gomina M, Bréard J. Characteristics of Hermès flax fibres as a function of their location in the stem and properties of the derived unidirectional composites. Compos Part A Appl Sci Manuf 2007;38:1912-21. doi:10.1016/j.compositesa.2007.03.006.

[2] Charlet K, Jernot JP, Gomina M, Bréard J, Morvan C, Baley C. Influence of an Agatha flax fibre location in a stem on its mechanical, chemical and morphological properties. Compos Sci Technol 2009;69:1399-403. doi:10.1016/j.compscitech.2008.09.002.

[3] Lefeuvre A, Bourmaud A, Morvan C, Baley C. Elementary flax fibre tensile properties: Correlation between stress-strain behaviour and fibre composition. Ind Crops Prod 2014;52:7629. doi:https://doi.org/10.1016/j.indcrop.2013.11.043.

[4] Lefeuvre A, Bourmaud A, Baley C. Optimization of the mechanical performance of UD flax/epoxy composites by selection of fibres along the stem. Compos Part A Appl Sci Manuf 2015;77:204-8. doi:10.1016/J.COMPOSITESA.2015.07.009.

[5] Scida D, Bourmaud A, Baley C. Influence of the scattering of flax fibres properties on flax/epoxy woven ply stiffness. Mater Des 2017;122:136-45. doi:10.1016/j.matdes.2017.02.094.

[6] Charlet K, Jernot J-PP, Breard J, Gomina M. Scattering of morphological and mechanical properties of flax fibres. Ind Crops Prod 2010;32:220-4. doi:https://doi.org/10.1016/j.indcrop.2010.04.015.

[7] Keryvin V, Lan M, Bourmaud A, Parenteau T, Charleux L, Baley C. Analysis of flax fibres 
viscoelastic behaviour at micro and nano scales. Compos Part A Appl Sci Manuf 2015;68:21925. doi:10.1016/j.compositesa.2014.10.006.

[8] Morvan C, Andème-Onzighi C, Girault R, Himmelsbach DS, Driouich A, Akin DE. Building flax fibres: more than one brick in the walls. Plant Physiol Biochem 2003;41:935-44. doi:10.1016/j.plaphy.2003.07.001.

[9] Lefeuvre A, Bourmaud A, Lebrun L, Morvan C, Baley C. A study of the yearly reproducibility of flax fiber tensile properties. Ind Crops Prod 2013;50:400-7. doi:https://doi.org/10.1016/j.indcrop.2013.07.035.

[10] Zeng X, Mooney SJ, Sturrock CJ. Assessing the effect of fibre extraction processes on the strength of flax fibre reinforcement. Compos Part A Appl Sci Manuf 2015;70:1-7. doi:10.1016/j.compositesa.2014.12.004.

[11] Baley C. Influence of kink bands on the tensile strength of flax fibers. J Mater Sci 2004;39:331-4. doi:10.1023/B:JMSC.0000007768.63055.ae.

[12] Andersons J, Poriķe E, Sparniņš E. The effect of mechanical defects on the strength distribution of elementary flax fibres. Compos Sci Technol 2009;69:2152-7. doi:https://doi.org/10.1016/j.compscitech.2009.05.010.

[13] Lefeuvre A, Duigou A Le, Bourmaud A, Kervoelen A, Morvan C, Baley C. Analysis of the role of the main constitutive polysaccharides in the flax fibre mechanical behaviour. Ind Crops Prod 2015;76:1039-48. doi:10.1016/J.INDCROP.2015.07.062.

[14] Bos HL, Van Den Oever MJA, Peters OCJJ. Tensile and compressive properties of flax fibres for natural fibre reinforced composites. J Mater Sci 2002;37:1683-92. doi:10.1023/A:1014925621252.

[15] NF T25-501-2: Fibres de renfort - Fibres de lin pour composites plastiques - Partie 2 : détermination des propriétés en traction des fibres élémentaires. AFNOR Stand 2015.

[16] Rayyaan R, Kennon WR, Potluri P, Akonda M. Morphological modification of the technical flax fibre bundles to improve the longitudinal tensile properties of flax fibre reinforced epoxy 
composites. ArXiv:180303366 2018.

[17] NF T25-501-3: Fibres de renfort - fibres de lin pour composites plastiques - Partie 3 : détermination des propriétés en traction des fibres techniques. AFNOR Stand 2015:16 pages.

[18] Bensadoun F, Verpoest I, Baets J, Müssig J, Graupner N, Davies P, et al. Impregnated fibre bundle test for natural fibres used in composites. J Reinf Plast Compos 2017;36:942-57. doi:10.1177/0731684417695461.

[19] Haag K, Müssig J. Scatter in tensile properties of flax fibre bundles: influence of determination and calculation of the cross-sectional area. J Mater Sci 2016;51:7907-17. doi:10.1007/s10853016-0052-z.

[20] International Orgnaization for Standardisation. Carbon fibre - Determination of tensile properties of resin-impregnated yarn. ISO 1061820042004.

[21] Mesogitis TS, Skordos AA, Long AC. Uncertainty in the manufacturing of fibrous thermosetting composites: A review. Compos Part A Appl Sci Manuf 2014;57:67-75. doi:10.1016/j.compositesa.2013.11.004.

[22] Baley C, Le Duigou A, Bourmaud A, Davies P. Influence of drying on the mechanical behaviour of flax fibres and their unidirectional composites. Compos Part A Appl Sci Manuf 2012;43:122633. doi:10.1016/j.compositesa.2012.03.005.

[23] Le Duigou A, Merotte J, Bourmaud A, Davies P, Belhouli K, Baley C. Hygroscopic expansion: A key point to describe natural fibre/polymer matrix interface bond strength. Compos Sci Technol 2017;151:228-33. doi:10.1016/j.compscitech.2017.08.028.

[24] Kim SH, Park CH. Direct impregnation of thermoplastic melt into flax textile reinforcement for semi-structural composite parts. Ind Crops Prod 2017;95:651-63. doi:10.1016/j.indcrop.2016.11.034.

[25] Potter KD. Understanding the origins of defects and variability in composites manufacture. Int. Conf. Compos. Mater. (ICCM)-17, 2009.

[26] Nguyen VH, Lagardère M, Park CH, Panier S. Permeability of natural fiber reinforcement for 
liquid composite molding processes. J Mater Sci 2014;49:6449-58. doi:10.1007/s10853-014$8374-1$.

[27] Pucci MF, Liotier PJ, Drapier S. Capillary effects on flax fibers - Modification and characterization of the wetting dynamics. Compos Part A Appl Sci Manuf 2015;77:257-65. doi:10.1016/j.compositesa.2015.03.010.

[28] Guo Z-S, Du S, Zhang B. Temperature field of thick thermoset composite laminates during cure process. Compos Sci Technol 2005;65:517-23. doi:10.1016/J.COMPSCITECH.2004.07.015.

[29] Rao J, Zhou Y, Fan M. Revealing the interface structure and bonding mechanism of coupling agent treated WPC. Polymers (Basel) 2018;10:266. doi:10.3390/polym10030266.

[30] Zhou Y, Fan M, Chen L. Interface and bonding mechanisms of plant fibre composites: An overview. Compos Part B Eng 2016;101:31-45. doi:10.1016/j.compositesb.2016.06.055.

[31] Pucci MF, Liotier PJ, Drapier S. Capillary wicking in flax fabrics - Effects of swelling in water. Colloids Surfaces A Physicochem Eng Asp 2016;498:176-84. doi:10.1016/j.colsurfa.2016.03.050.

[32] Baley C, Busnel F, Grohens Y, Sire O. Influence of chemical treatments on surface properties and adhesion of flax fibre-polyester resin. Compos Part A Appl Sci Manuf 2006;37:1626-37. doi:10.1016/j.compositesa.2005.10.014.

[33] Cantero G, Arbelaiz A, Llano-Ponte R, Mondragon I. Effects of fibre treatment on wettability and mechanical behaviour of flax/polypropylene composites. Compos Sci Technol 2003;63:1247-54. doi:10.1016/S0266-3538(03)00094-0.

[34] Cadu T, Berges M, Sicot O, Person V, Piezel B, Van Schoors L, et al. What are the key parameters to produce a high-grade bio-based composite? Application to flax/epoxy UD laminates produced by thermocompression. Compos Part B Eng 2018;150:36-46.

[35] Gurit. DATASHEET / PRIME ${ }^{\mathrm{TM}} 27$ - Epoxy Infusion System n.d.:1-8. www.gurit.com//media/Gurit/Datasheets/prime-27.pdf (accessed on 30 July 2019)

[36] Ray D, Sarkar BK, Das S, Rana AK. Dynamic mechanical and thermal analysis of vinylester- 
resin-matrix composites reinforced with untreated and alkali-treated jute fibres. Compos Sci Technol 2002;62:911-7. doi:10.1016/S0266-3538(02)00005-2.

[37] Romanzini D, Lavoratti A, Ornaghi HL, Amico SC, Zattera AJ. Influence of fiber content on the mechanical and dynamic mechanical properties of glass/ramie polymer composites. Mater Des 2013;47:9-15. doi:10.1016/J.MATDES.2012.12.029.

[38] Yang H. Study of a unidirectional flax reinforcement for biobased composite. $\mathrm{PhD}$ thesis, Normandie Université, 2017.

[39] Campana C, Leger R, Sonnier R, Ferry L, Ienny P. Effect of post curing temperature on mechanical properties of a flax fiber reinforced epoxy composite. Compos Part A Appl Sci Manuf 2017;107:171-9. doi:10.1016/j.compositesa.2017.12.029.

[40] Crowson RJ, Arridge RGC. The elastic properties in bulk and shear of a glass bead-reinforced epoxy resin composite. J Mater Sci 1977;12:2154-64. doi:10.1007/BF00552236.

[41] Fernandez JA, Le Moigne N, Caro-Bretelle A, El Hage R, Le Duc A, Lozachemur M, et al. Role of flax cell wall components on the microstructure and transverse mechanical behaviour of flax fabrics reinforced epoxy biocomposites. Ind Crops Prod 2016;85:93-108. doi:10.1016/J.INDCROP.2016.02.047.

[42] Le Duigou A, Kervoelen A, Le Grand A, Nardin M, Baley C. Interfacial properties of flax fibreepoxy resin systems: Existence of a complex interphase. Compos Sci Technol 2014;100:152-7. doi:10.1016/J.COMPSCITECH.2014.06.009.

[43] Li M, Yuan C, Wang SK, Gu YZ, Potter K, Zhang ZG. Evolution of the wettability between carbon fiber and epoxy as a function of temperature and resin curing. J Appl Polym Sci 2013;128:4095-101. doi:10.1002/app.38634.

[44] Liotier P-J, Pucci MF, Drapier S. Evaluation by wicking tests of capillary pressure as function of temperature for uncured resins. 14th Int. Conf. flow Process. Compos. Mater., Lulea: 2018.

[45] Bensadoun F. In-service behaviour of flax fibre reinforced composites for high performance applications. PhD thesis, KU Leuven, 2016. 
[46] Bourmaud A, Morvan C, Bouali A, Placet V, Perré P, Baley C. Relationships between microfibrillar angle, mechanical properties and biochemical composition of flax fibers. Ind Crops Prod 2013;44:343-51. doi:https://doi.org/10.1016/j.indcrop.2012.11.031.

[47] Moudood A, Hall W, Öchsner A, Li H, Rahman A, Francucci G. Effect of moisture in flax fibres on the quality of their composites. J Nat Fibers 2019;16:209-24.

doi:10.1080/15440478.2017.1414651.

[48] Bismarck A, Aranberri-Askargorta I, Springer J, Lampke T, Wielage B, Stamboulis A, et al. Surface characterization of flax, hemp and cellulose fibers; Surface properties and the water uptake behavior. Polym Compos 2002;23:872-94. doi:10.1002/pc.10485.

[49] Martin N, Davies P, Baley C. Comparison of the properties of scutched flax and flax tow for composite material reinforcement. Ind Crop Prod 2014;61:284-92. doi:10.1016/j.indcrop.2014.07.015.

[50] Kersani M, Lomov S V, Van Vuure AW, Bouabdallah A, Verpoest I. Damage in flax/epoxy quasi-unidirectional woven laminates under quasi-static tension. J Compos Mater 2015;49:40313. doi:10.1177/0021998313519282.

[51] Koh R, Madsen B. Strength failure criteria analysis for a flax fibre reinforced composite. Mech Mater 2018;124:26-32. doi:10.1016/J.MECHMAT.2018.05.005.

[52] Oksman K. High quality flax fibre composites manufactured by the resin transfer moulding process. J Reinf Plast Compos 2001;20:621-7. doi:10.1106/CA5A-6FAX-VJRB-80P0.

[53] Berges M, Léger R, Placet V, Person V, Corn S, Gabrion X, et al. Influence of moisture uptake on the static, cyclic and dynamic behaviour of unidirectional flax fibre-reinforced epoxy laminates. Compos Part A Appl Sci Manuf 2016;88:165-77. doi:10.1016/J.COMPOSITESA.2016.05.029. 


\section{Figure captions}

Figure 1. Images of technical and elementary flax fibers (White arrows indicate the location of kink bands on an individual flax fiber): (a) SEM images. (b) Polarized light microscopy.

Figure 2. Schematic of the manufacturing procedure for composite and neat resin plates

Figure 3. Result of DSC analyses for different cure cycles: (a) Heat flow evolution during isothermal DSC measurements for different cure cycles (b). Time-dependent evolution of the degree of cure (The degree of cure at the end of isothermal compression steps is indicated by the horizontal lines).

Figure 4. SEM images of fracture surface with a magnifications of $\times 60$ (left) and of $\times 300$ (right). (Cracks are indicated by the arrows). [SEM acceleration voltage: $15 \mathrm{kV}]$.

Figure 5. SEM images showing the interfacial cohesion and decohesion for different cure cycles: (a) At the macro and meso-scales (Cracks at the interface of fibers are highlighted based on a gray level histogram thresholding). (b) At the scale of individual fibers [SEM acceleration voltage: 10kV].

Figure 6. Stress-strain curves of some representative UD composite samples.

Figure 7. Results of tensile tests and back-calculated tensile properties: (a) Tensile moduli of composite, of neat resin samples and of fibers (back-calculated, BC). (b) Tensile strengths of composite, of neat resin samples and of fibers (back-calculated, BC).

Figure 8. SEM images of fractured surfaces of composite samples [SEM acceleration voltage: $15 \mathrm{kV}]$.

Figure 9. Comparison of composite strength and back-calculated fiber strength between literature and this work.

\section{Table captions}

Table 1. Glass transition temperatures of neat epoxy and composites (Standard deviation in the parenthesis)

Table 2. Fiber mass, fiber volume fraction and residual void content of composites plates 
Figure 1

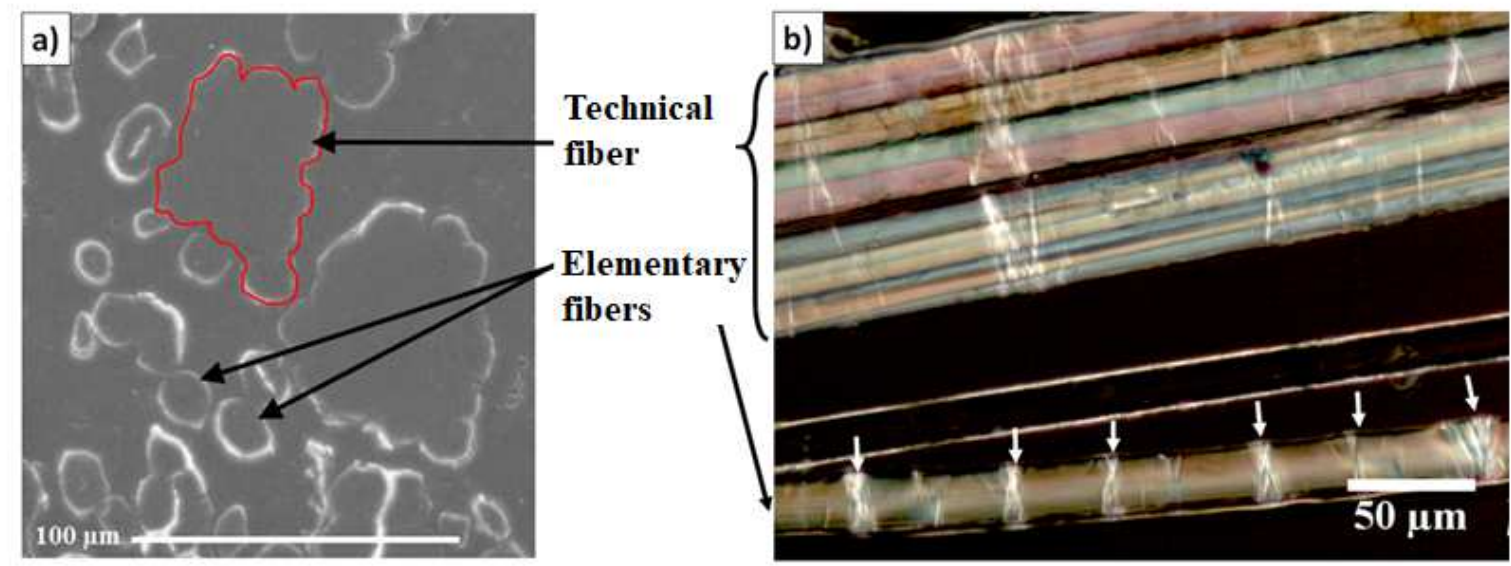

Figure 2

1. Cutting flax fiber tape 2 . Drying $\left(60^{\circ} \mathrm{C} / 14 \mathrm{~h}\right)$

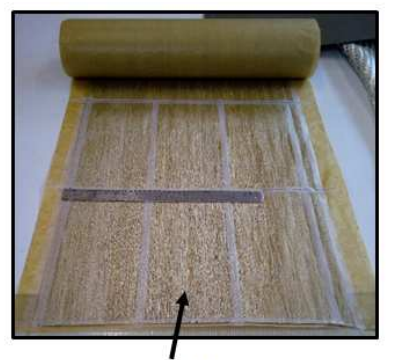

Flaxtape $^{\mathrm{TM}} 110$

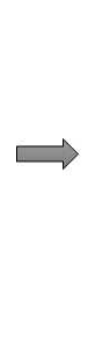

UD flax fiber layers

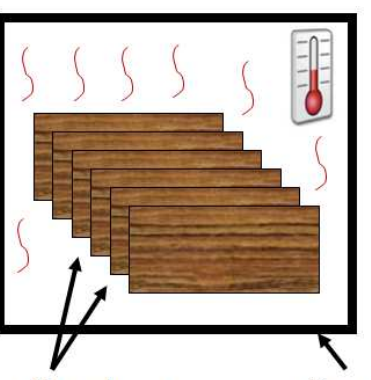

Oven

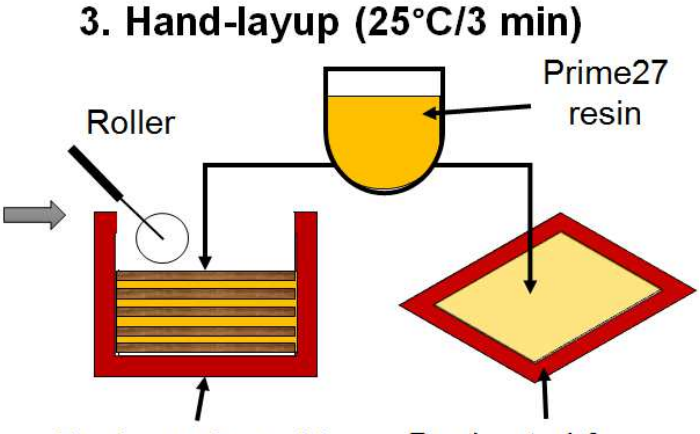

Pre-heated mould

Pre-heated frame

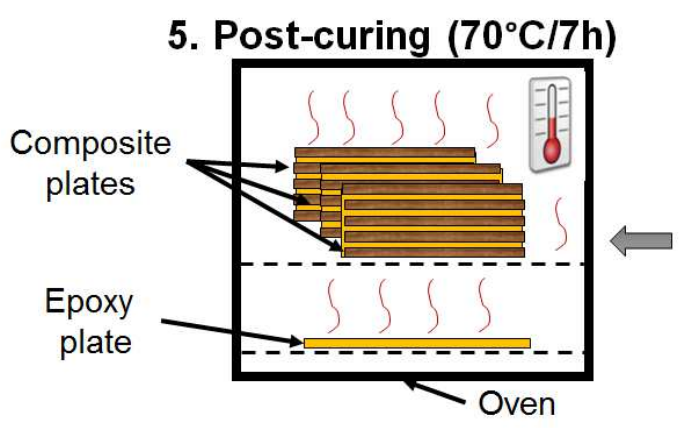

4. Isothermal compression

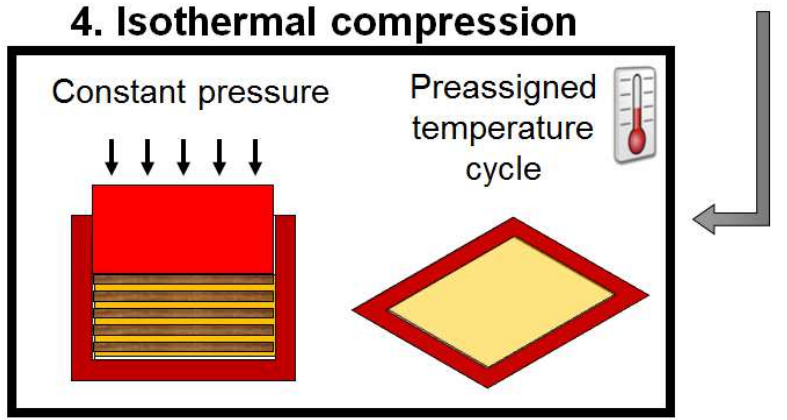


Figure 3a

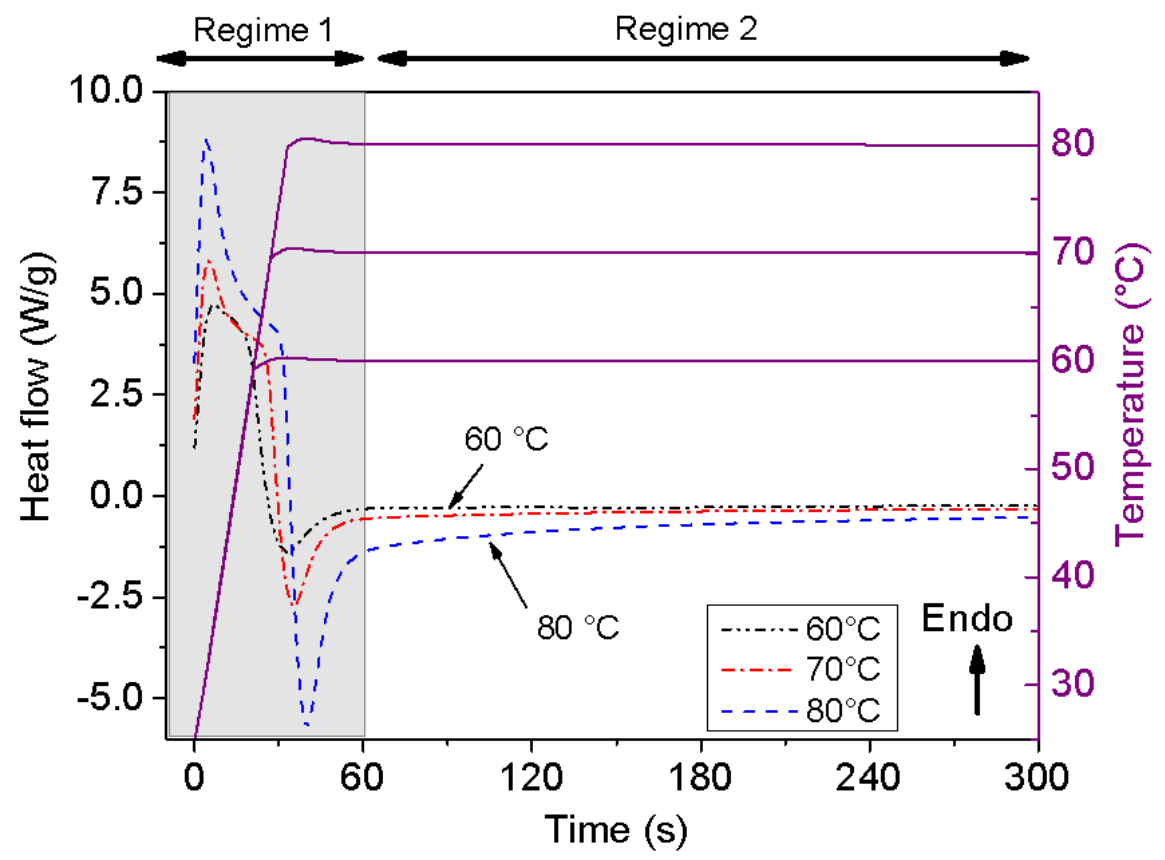

Figure 3b

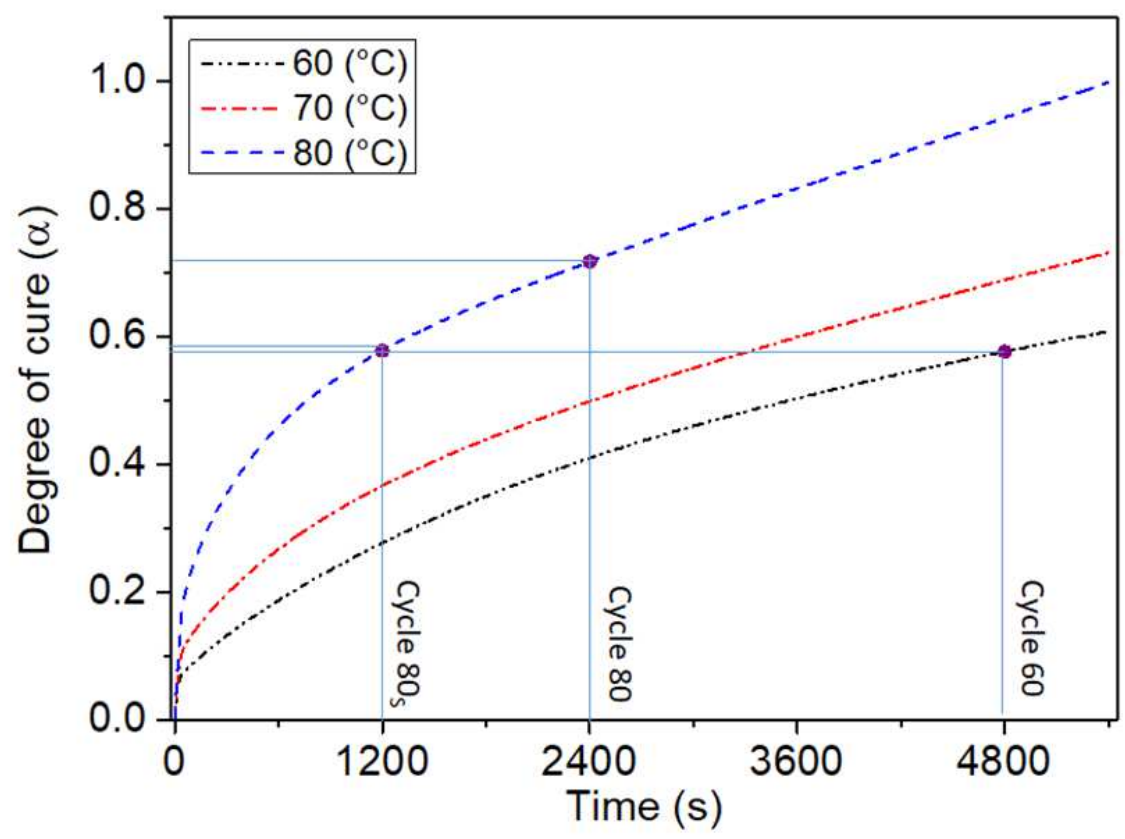


Figure 4
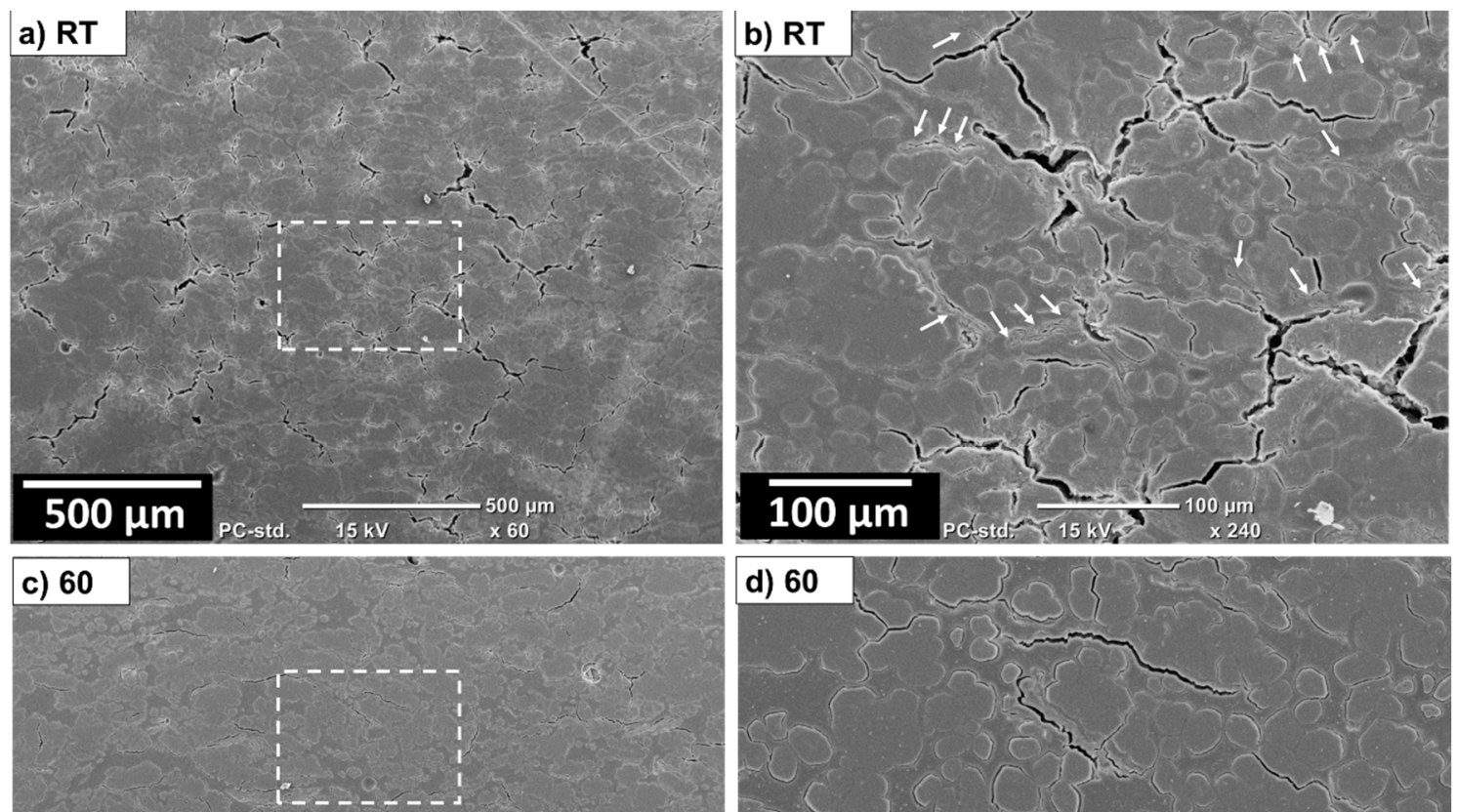

\section{d) 60}
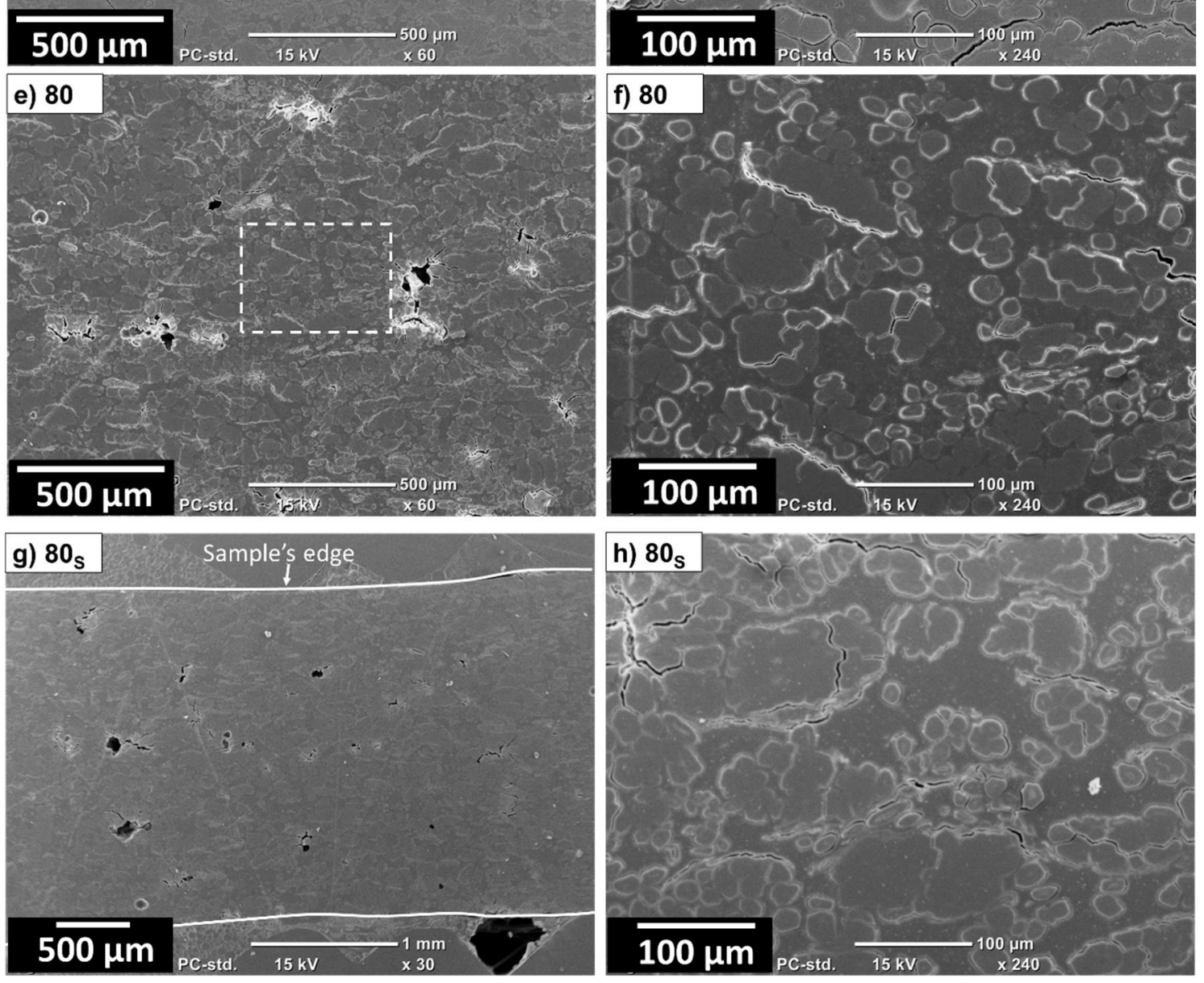
Figure 5a
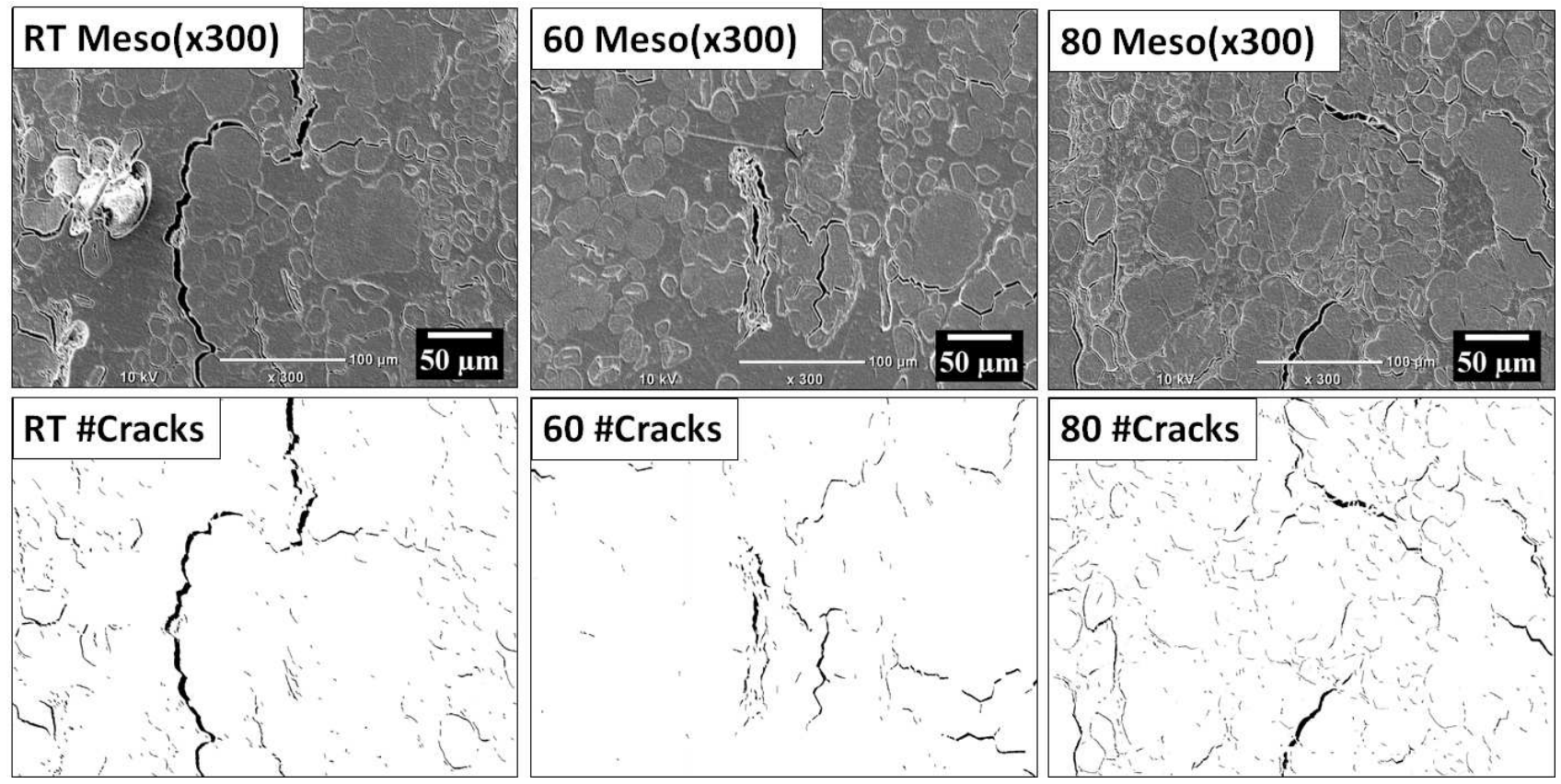

Figure 5b
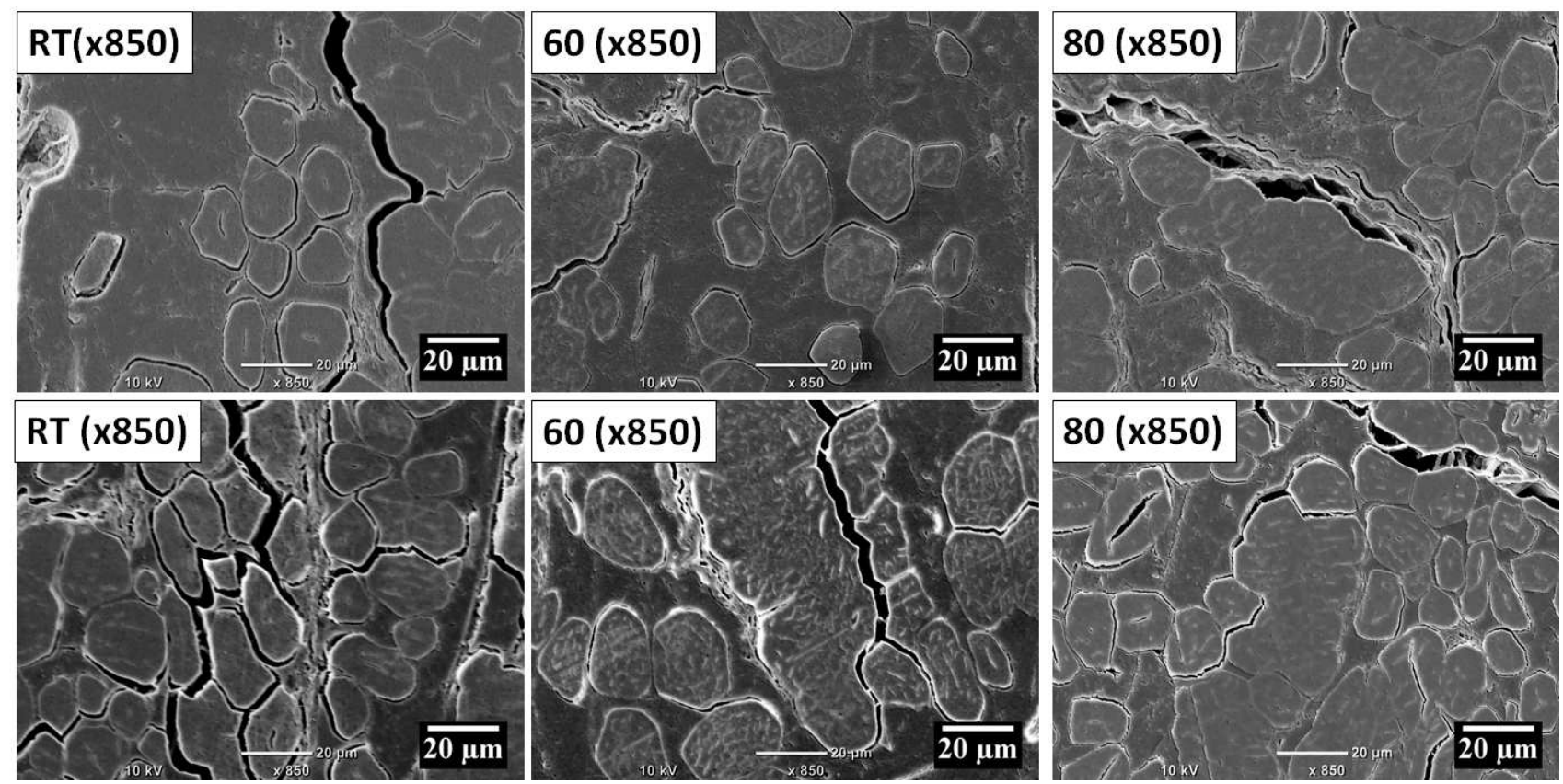
Figure 6

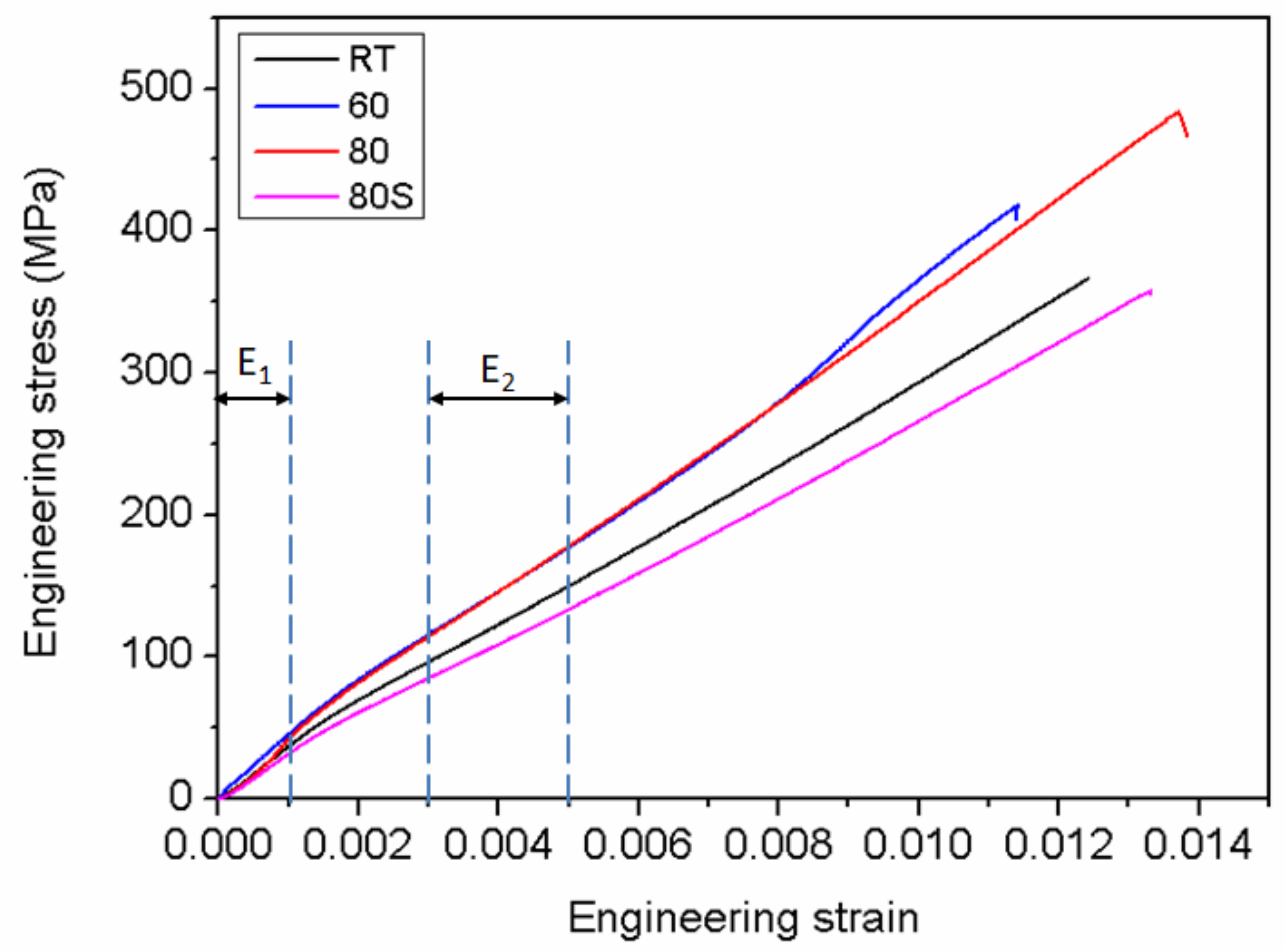


Figure 7a

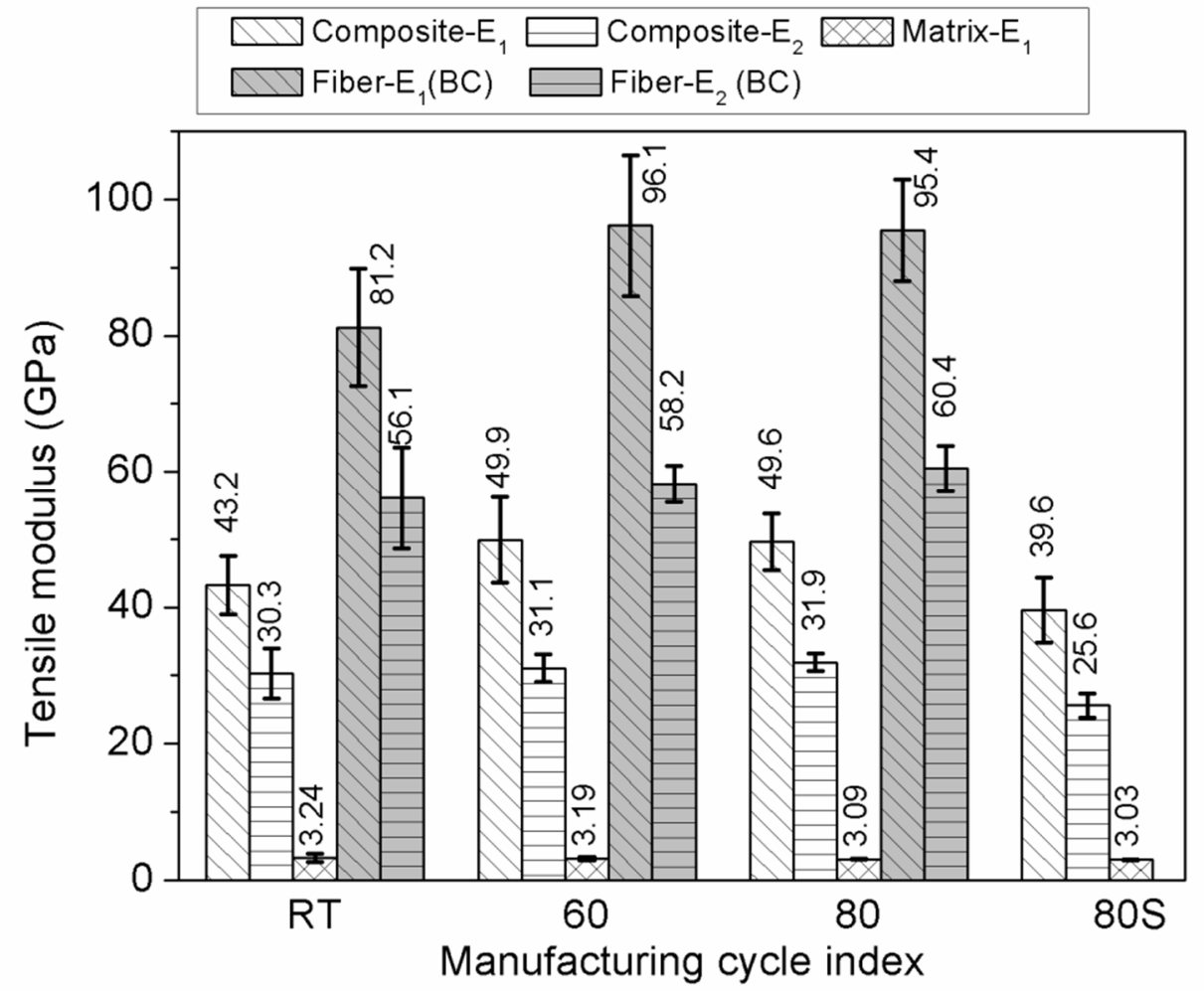

Figure $7 b$

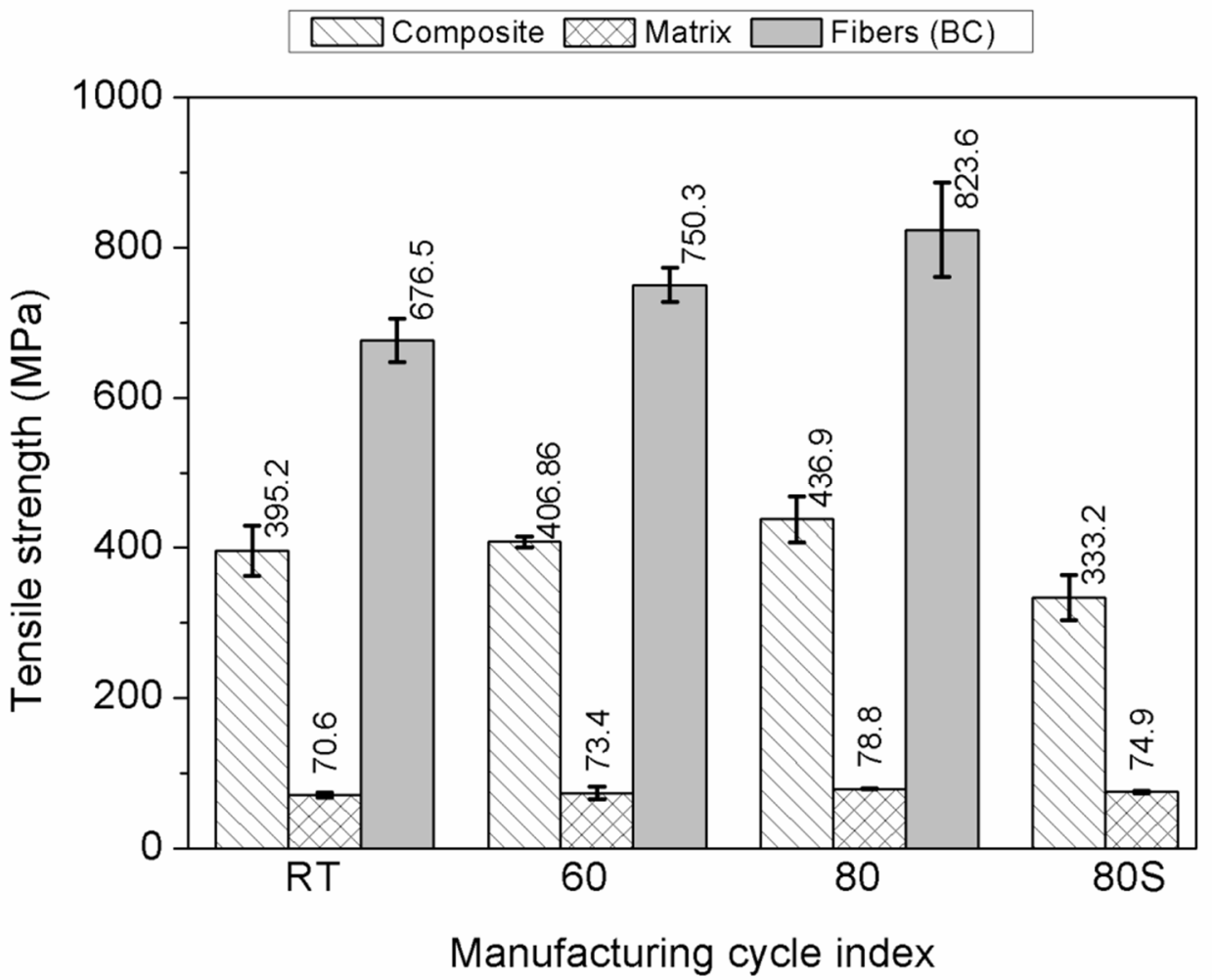


Figure 8
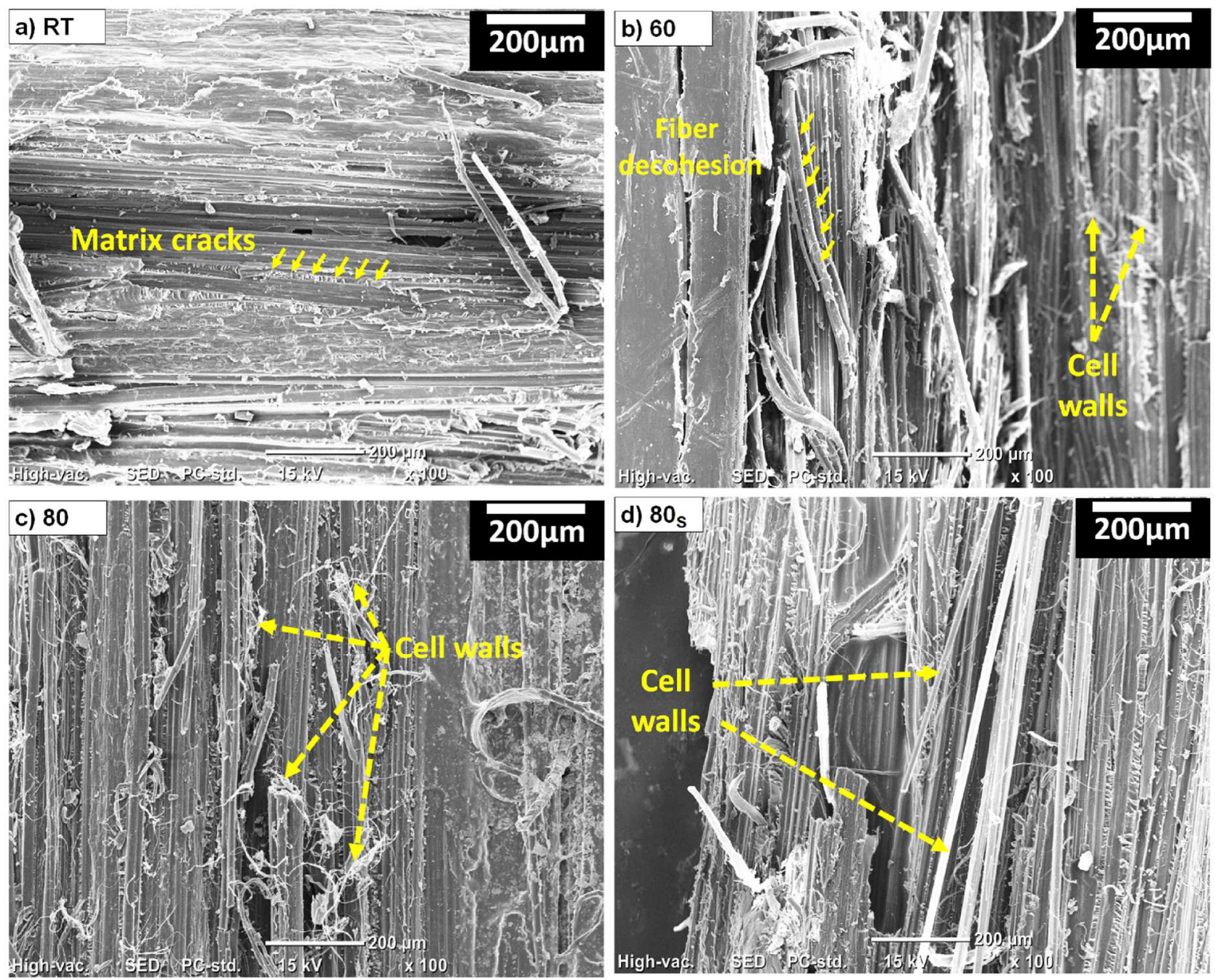
Figure 9

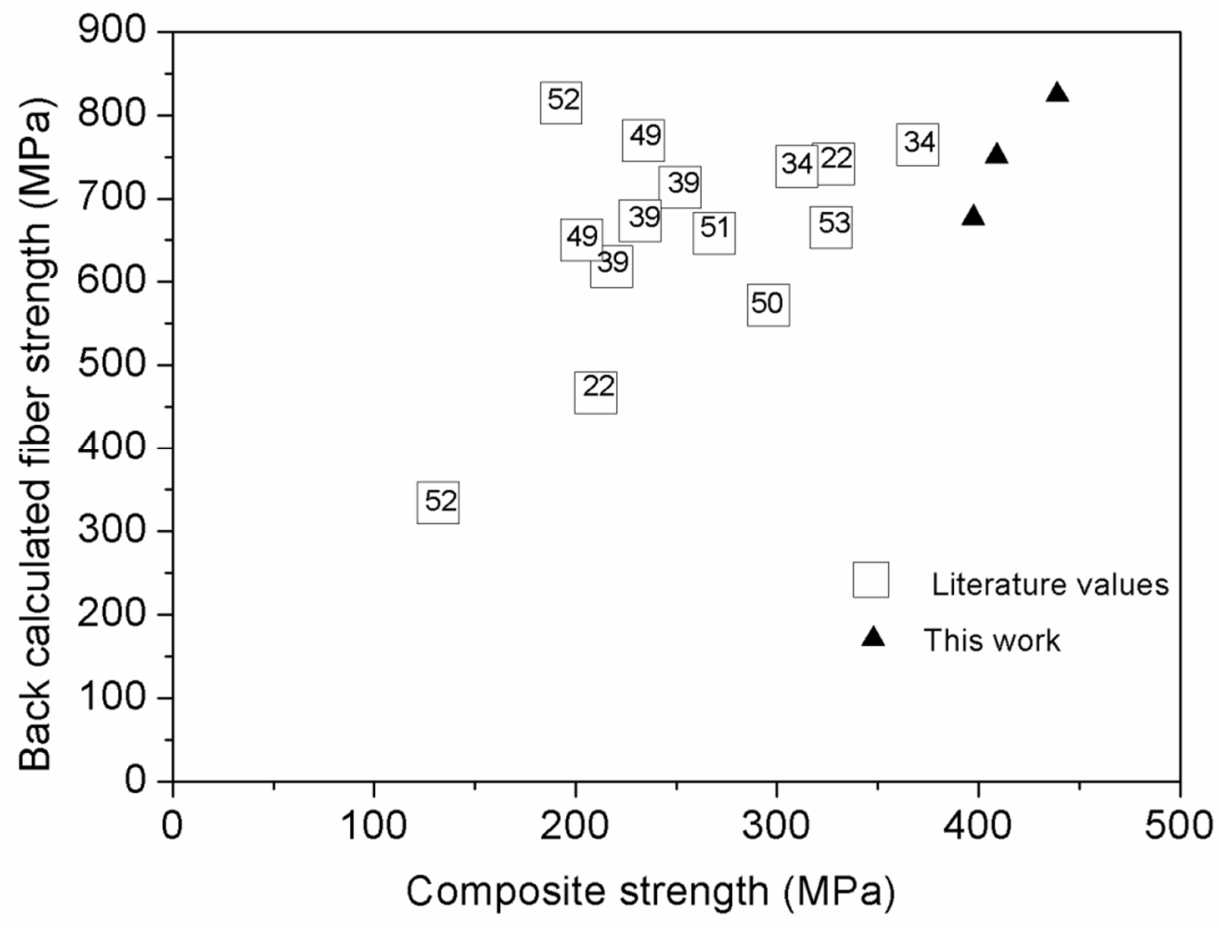


Table 1

\begin{tabular}{ccl}
\hline Cycle & Matrix & Composite \\
\hline RT & $71.5( \pm 0.6)$ & $75.2( \pm 0.7)$ \\
60 & $78.0( \pm 0.6)$ & $79.7( \pm 0.5)$ \\
80 & $78.2( \pm 0.5)$ & $82.9( \pm 0.8)$ \\
$80_{\mathrm{S}}$ & $75.5( \pm 0.8)$ & $75.2( \pm 0.8)$ \\
\hline
\end{tabular}

Table 2

\begin{tabular}{cccccc}
\hline \multirow{2}{*}{ Cycle } & Plate index & $\begin{array}{c}\text { Fiber mass } \\
(\mathbf{g})\end{array}$ & $\begin{array}{c}\text { Sample thickness } \\
(\mathbf{m m})\end{array}$ & $\begin{array}{c}\text { Fiber volume fraction } \\
(\%)\end{array}$ & $\begin{array}{c}\text { Void content } \\
(\%)\end{array}$ \\
\hline \multirow{3}{*}{ RT } & 1 & 17.7 & 1.7 & 52 & 1.8 \\
& 2 & 18.2 & 1.8 & 51 & 1.9 \\
& 3 & 18.1 & 1.8 & 51 & 2.1 \\
\hline \multirow{3}{*}{60} & 1 & 17.5 & 2.0 & 53 & 1.4 \\
& 2 & 17.4 & 2.0 & 51 & 2.2 \\
& 3 & 17.0 & 2.0 & 52 & 1.4 \\
\hline \multirow{3}{*}{80} & 1 & 17.8 & 1.7 & 49 & 1.5 \\
& 2 & 18.0 & 1.7 & 51 & 1.2 \\
& 3 & 17.7 & 1.7 & 51 & 2.1 \\
\hline \multirow{3}{*}{$80_{S}$} & 1 & 18.4 & 2.0 & 50 & 2.3 \\
& 2 & 17.8 & 1.9 & 51 & 2.2 \\
& 3 & 17.1 & 2.0 & 53 & 2.6 \\
\hline
\end{tabular}

